\title{
Perencanaan Ulang Electric Submersible Pump pada Sumur L5A-MRS
}

\author{
Tio Fariz Siswanto \\ PEM Akamigas
}

\begin{abstract}
Abstrak
Pada sumur L5A-MRS terpasang ESP ING 3200 dengan 130 stages. Dari hasil evaluasi, ESP ING 3200 tidak bekerja dengan baik. Efisiensi pompa sebesar 55\%, pompa dalam kondisi kelebihan beban muatan, stages yang terpasang (130 stages) kurang dari stages minimal yang dibutuhkan (174 stages) untuk mengalirkan fluida sampai ke permukaan, Diperlukan perencanaan ulang agar pompa dapat beroperasi dengan optimal. Pompa desain adalah ESP ING 4000, 145 stages tersedia, Q desain $4450 \mathrm{bpd}, 60 \mathrm{~Hz}$, efisiensi pompa 66\%, pada PSD $4000 \mathrm{ft}$.
\end{abstract}

Kata kunci: Desain ESP, Evaluasi ESP

\begin{abstract}
At L5A-MRS well installed ESP ING 3200 with 130 stages. From the evaluation results, the ESP ING 3200 does not work well. The pump efficiency is 55\%, the pump is in overloaded condition, available stages (130 stages) are less than the required minimum stages (174 stages) to lift the fluid up to the surface. It is necessary to do electric submersible pump re-design. Pump design is ESP ING 4000, 145 stages available, Q design 4450 bpd, $60 \mathrm{~Hz}$, pump efficiency 66\%, on PSD 4000 $f t$.
\end{abstract}

Keywords: ESP design, ESP evaluation

\section{Pendahuluan}

Produksi minyak dari suatu sumur dapat dilakukan dengan dua cara, yaitu dengan Metode Sembur Alam (Natural Flow Method) dan Metode Pengangkatan Buatan (Artificial Lift Method). Pada sumur sembur alam, tekanan reservoir mampu mengangkat fluida produksi dari dasar sumur sampai ke permukaan dan mengalirkannya sampai ke fasilitas proses. Metode pengangkatan buatan digunakan apabila tekanan reservoir sudah tidak mampu lagi memproduksikan minyak dengan sembur alam. Salah satu metode pengangkatan buatan adalah Electric Submersible Pump (ESP).
Pompa ESP merupakan pompa sentrifugal bertingkat, dengan tiap tingkat terdiri dari impeller dan diffuser. Fluida yang masuk melalui pump intake akan bergerak menuju tingkat pertama pompa. Putaran impeller tersebut akan memberikan gaya dorong pada fluida, sehingga fluida tersebut akan memiliki energi lebih besar dari pada sebelumnya. Diffuser akan mengarahkan fluida untuk bergerak menuju impeller pada tingakat berikutnya dan proses tersebut akan terus berjalan sampai tingkat terakhir.

Dalam penulisan journal ini, penulis melakukan evaluasi permasalahan pompa yang 
terpasang pada sumur L5A-MRS. Dilakukan desain ulang terhadap pompa yang terpasang dengan harapan pompa desain dapat bekerja optimal dengan efisiensi terbaik dan mendapatkan keuntungan untuk perusahaan.

\section{Metode Penelitian}

\section{A. Subjek Penelitian}

Subjek dalam penulisan jurnal ini adalah evaluasi pompa ESP dan desain ulang pompa ESP yang terpasang.

\section{B. Objek Penelitian}

Objek dalam penulisan jurnal ini adalah model kondisi keadaan pompa ESP yang terpasang dan keadaaan pompa yang akan dipasang (pompa desain).

\section{Tahapan Penelitian}

Berikut ini tahapan-tahapan yang akan digunakan penulis selama melakukan penelitian:

1. Studi pustaka

2. Informasi umum dan asumsi

3. Evaluasi pompa ESP terpasang

4. Menentukan Q desain dan Pwf desain

5. Perencaan ulang ESP

6. Analisis hasil perhitungan

7. Evaluasi data hasil analisis

8. Simpulan dan Saran

\section{Pengumpulan Data}

Data-data yang diperlukan untuk melakukan penelitian meliputi:

1. Data produksi sumur

2. Data reservoir sumur

3. Data ketersediaan pompa

\section{E. Pengolahan Data}

Data akan dianalisis dan diolah dalam bentuk tabel maupun grafik dengan menggunakan microsoft excel. Hal ini bertujuan agar parameter evaluasi dan hasil analisis dapat diketaui dengan jelas.

\section{Hasil Penelitian dan Pembahasan}

Dalam bab ini disajikan tahapan evaluasi ESP yang terpasang (ING 3200) dan perencanaan ulang terhadap ESP yang terpasang dengan harapan desain pompa ESP hasil desain (ING 4000) dapat bekerja dengan optimal.

Evaluasi pada pompa ESP ING 3200 meliputi evaluasi frekuensi dan evaluasi stages yang terpasang.

Untuk mengevaluasi frekuensi-frekuensi diperlukan nilai recommended flow range pada frekuensi 50-60 Hz. Nilai recommended flow range didapatkan dari Pump Performance Curve dan disajikan dalam tabel berikut.

Tabel 1. Recommended Flow Range ING 3200 pada 50-60 Hz

\begin{tabular}{|l|c|}
\hline $\begin{array}{c}\text { Frekuensi } \\
\text { (Hz) }\end{array}$ & $\begin{array}{c}\text { Recommended Flow Range } \\
\text { (BFPD) }\end{array}$ \\
\hline $\mathbf{5 0}$ & $1667-3600$ BFPD \\
\hline $\mathbf{5 1}$ & $1700-3672$ BFPD \\
\hline $\mathbf{5 2}$ & $1733-3744$ BFPD \\
\hline $\mathbf{5 3}$ & $1767-3816$ BFPD \\
\hline $\mathbf{5 4}$ & $1800-3888$ BFPD \\
\hline $\mathbf{5 5}$ & $1833-3960$ BFPD \\
\hline $\mathbf{5 6}$ & $1867-4032$ BFPD \\
\hline $\mathbf{5 7}$ & $1900-4104$ BFPD \\
\hline $\mathbf{5 8}$ & $1933-4176$ BFPD \\
\hline $\mathbf{5 9}$ & $1967-4248$ BFPD \\
\hline $\mathbf{6 0}$ & $2000-4320$ BFPD \\
\hline
\end{tabular}

Berdasarkan data well test, rate yang diproduksikan oleh pompa ING 3200 sebanyak 4310 BFPD. Rate sebanyak 4310 BFPD tidak direkomendasikan untuk diproduksi pada frekuensi $50-59 \mathrm{~Hz}$ dikarenakan rate 4310 BFPD diatas batas recommended flow range $\mathrm{di}$ frekuensi 50-59 Hz. Apabila tetap diproduk- 
sikan pada frekuensi $50-59 \mathrm{~Hz}$, maka pompa akan mengalami kondisi upthrust dan dapat menyebabkan pompa rusak.

Frekuensi yang memungkinkan untuk dipakai adalah frekuensi $60 \mathrm{~Hz}$ (2000 - 4320 BFPD), akan tetapi pada frekuensi $60 \mathrm{~Hz}$ dengan rate produksi 4310 BFPD mendekati batas atas recommended flow range sehingga efisiensi pompa menurun sampai di bawah $57 \%$ dan pompa tidak beroperasi pada efisiensi terbaik.

Untuk mengevaluasi stages yang terpasang, diperlukan Pump Performance Curve ING 3200 dan data jumlah stages terpasang. Jumlah stages terpasang adalah 130 stages. Untuk Pump Performance Curve menggunakan frekuensi yang memiliki nilai recommended flow range mencakup rate produksi 4310 bpd $(\mathrm{Q}$ gross), yaitu pada frekuensi $60 \mathrm{~Hz}$ dengan nilai recommended flow range $2000-4320$ bpd dan jumlah stages 130 stages. Plot nilai rate produksi 4310 bpd pada pump performance curve, maka akan didapatkan nilai pump efficiency, motor load, dan head.

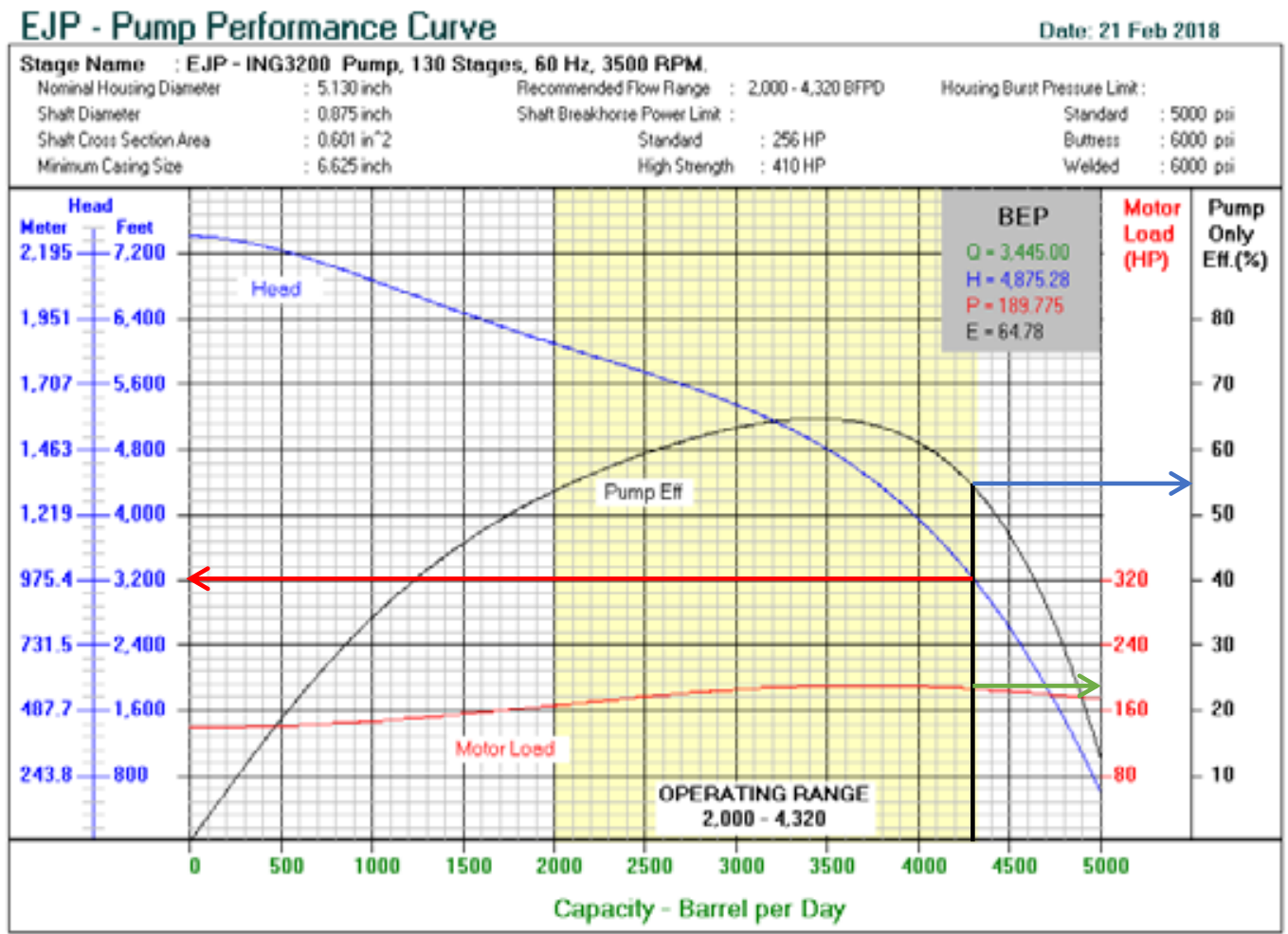

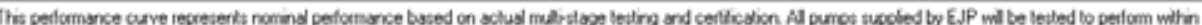

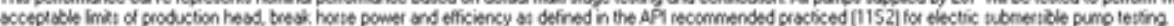

Gambar 1. Pump Performance Curve ING $320060 \mathrm{~Hz}$, 130 Stages

Berdasarkan hasil plot didapatkan nilai efsiensi pompa sebesar 55\%, beban motor sebesar $192 \mathrm{HP}$, dan head sebesar $3200 \mathrm{ft}$ atau $24.615 \mathrm{ft} /$ stages.

Untuk mengetahui jumlah stages minimal yang dibutuhkan, perlu dilakukan perhitungan Total Dynamic Head (TDH) sebagai berikut:
Menghitung $\mathrm{SG}_{\mathrm{L}}$ (Spesific Gravity) campuran menggunakan persamaan:

$\mathrm{SG}_{\mathrm{L}}=($ Fraksi air $\times \mathrm{SG}$ air $)+($ Fraksi minyak $\times \mathrm{SG}$ minyak)

$\mathrm{SG}_{\mathrm{L}}=(98 \% \times 1.02)+(2 \% \times 0.985)$

$\mathrm{SG}_{\mathrm{L}}=1.0193$ 
Menghitung PIP (Pump Intake Pressure)

menggunakan persamaan:

$$
\begin{aligned}
& \text { PIP }=\text { Pwf }-\left[\frac{(\text { DatumDepth-PumpDepth }) \times S G_{L}}{2.31 f t / p s i}\right] \\
& \text { PIP }=722,9-\left[\frac{(5302.658-3711.942) \times 1,0193}{2.31 f t / p s i}\right] \\
& \text { PIP }=21 \text { psi }
\end{aligned}
$$

Menghitung Net Dynamic Lift menggunakan persamaan:

Net Dynamic Lift $=$ PSD $-\frac{\operatorname{PIP} \times 2,31 \mathrm{ft} / \mathrm{psi}}{\mathrm{SGL}}$

Net Dynamic Lift $=3711,942-\frac{21 \times 2,31 \mathrm{ft} / \mathrm{psi}}{1,0193}$

Net Dynamic Lift $=3664.37 \mathrm{ft}$

Menghitung nilai friction loss pada ID tubing 2.992 inch pada $\mathrm{Q}=4310 \mathrm{bpd}$ dengan persamaan:

$\mathrm{F}=2.083 \times\left(\frac{100}{\mathrm{C}}\right)^{1.85} \times \frac{\left(\frac{\mathrm{Q}}{34.3}\right)^{1.85}}{(\mathrm{ID})^{4.8655}}$

$\mathrm{F}=2.083 \times\left(\frac{100}{94}\right)^{1.85} \times \frac{\left(\frac{4310}{34.3}\right)^{1.85}}{(2.992)^{4.8655}}$

\section{$\mathrm{F}=86.31 \mathrm{ft} / 1000$}

Menghitung total friction loss sepanjang PSD:

Total Friction Loss $=$ F $\times$ PSD

Total Friction Loss $=\frac{86.31}{1000} \times 3711.942$

Total Friction Loss $=320.4 \mathrm{ft}$

Konversi wellhead pressure dalam satuan $\mathrm{ft}$ dengan persamaan:

$\mathrm{WHP}(\mathrm{ft})=\frac{\mathrm{WHP}(\mathrm{psi}) \times 2.31 \mathrm{ft} / \mathrm{psi}}{\mathrm{SGl}}$

WHP $(\mathrm{ft})=\frac{130 \times 2.31 \mathrm{ft} / \mathrm{psi}}{1.0193}$

WHP $(\mathrm{ft})=294.6 \mathrm{ft}$

Menghitung TDH (Total Dynamic Head) dengan persamaan:

$\mathrm{TDH}=$ Net Dynamic Lift + Total Friction Loss

$$
+ \text { WHP (ft) }
$$

$\mathrm{TDH}=3664.377+320.4+294.6)$

$\mathrm{TDH}=4279 \mathrm{ft}$

Jumlah stages minimal yang dibutuhkan agar fluida dapat mengalir ke permukaan (stages required) dapat diketahui dengan persamaan:

Stages Required $=\frac{\mathrm{TDH}}{\text { head/stages }}$

Stages Required $=\frac{4279}{24.615}$

Stages Required $=173.8$ (174 stages)

Stages yang terpasang (available stages) adalah 130 stages, sedangkan jumlah stages minimal yang dibutuhkan untuk mengalirkan fluida sampai ke permukaan (stages required) adalah 174 stages, maka secara teori fluida tidak bisa mengalir sampai ke permukaan karena jumlah available stages dibawah jumlah stages yang dibutuhkan untuk mengalirkan fluida sampai ke permukaan (stages required). Jika fluida dapat mengalir sampai ke permukaan, maka pompa dalam keadaan kelebihan beban muatan (overload) karena perbedaaan stages yang dibutuhkan untuk mengalirkan fluida (174 stages) cukup besar dibandingkan dengan stages yang terpasang (130 stages).

Oleh karena itu, perlu dilakukan perencanaan ulang terhadap pompa yang terpasang agar sumur tetap dapat berproduksi dengan rate yang besar dan pompa yang digunakan untuk memproduksikan rate tersebut bekerja secara optimal pada efisiensi yang baik (diatas $60 \%$ ) dengan stages yang tersedia.

Perencaan ulang ESP meliputi perhitungan Inflow Performance Relationship (IPR), menentukan Q desain dan Pwf desain, pemilihan pompa, dan perhitungan jumlah stages yang dibutuhkan.

IPR pada sumur L5A-MRS menggunakan Metode Vogel dengan langkah perhitungan sebagai berikut:

Menghitung nilai $\mathrm{Q}_{\text {maksimum' }}$ menggunakan persamaan: 


$$
\begin{aligned}
& \mathrm{Q} \max =\frac{(\mathrm{Q} \text { test })}{1-0.2\left(\frac{\mathrm{Pwf}}{\mathrm{Pr}}\right)-0.8\left(\frac{\mathrm{Pwf}}{\mathrm{Pr}}\right)^{2}} \\
& \mathrm{Q} \max =\frac{(4310)}{1-0.2\left(\frac{722.9}{2074.5}\right)-0.8\left(\frac{722.9}{2074.5}\right)^{2}}
\end{aligned}
$$

$\mathrm{Q} \max =5173.068 \mathrm{bpd}$

Menghitung nilai Q pada berbagai Pwf asumsi:

Q pada Pwf $=0$ psi ( $Q$ max $)$

$\mathrm{Q}=(5173.068) \times\left(1-0.2\left(\frac{0}{2074.5}\right)-0.8\left(\frac{0}{2074.5}\right)^{2}\right)=5173.068$

$\mathrm{Q}$ pada $\mathrm{Pwf}=200 \mathrm{psi}$

$\mathrm{Q}=(5173.068) \times\left(1-0.2\left(\frac{200}{2074.5}\right)-0.8\left(\frac{200}{2074.5}\right)^{2}\right)=5034.857$

$Q$ pada $P w f=2000$ psi

$\mathrm{Q}=(5173.068) \times\left(1-0.2\left(\frac{2000}{2074.5}\right)-0.8\left(\frac{2000}{2074.5}\right)^{2}\right)=329.06$

Q pada $\mathrm{Pwf}=\mathrm{Pr}=2074.5 \mathrm{psi}$

$Q=$

$(5173.068) \times\left(1-0.2\left(\frac{2074.5}{2074.5}\right)-0.8\left(\frac{2074.5}{2074.5}\right)^{2}\right)=0$

Tabulasi nilai Pwf asumsi dan Q pada Pwf asumsi:

Tabel 2. Pwf asumsi dan Q pada Pwf asumsi

\begin{tabular}{|l|c|}
\hline \multicolumn{1}{|c|}{$\begin{array}{c}\text { Pwf asumsi } \\
\text { (psi) }\end{array}$} & $\begin{array}{c}\text { Q pada Pwf asumsi } \\
\text { (bbl) }\end{array}$ \\
\hline $\mathbf{0}$ & 5173.068 \\
\hline $\mathbf{2 0 0}$ & 5034.857 \\
\hline $\mathbf{4 0 0}$ & 4819.714 \\
\hline $\mathbf{6 0 0}$ & 4527.641 \\
\hline $\mathbf{8 0 0}$ & 4158.637 \\
\hline $\mathbf{1 0 0 0}$ & 3712.702 \\
\hline $\mathbf{1 2 0 0}$ & 3189.835 \\
\hline $\mathbf{1 4 0 0}$ & 2590.038 \\
\hline $\mathbf{1 6 0 0}$ & 1913.31 \\
\hline $\mathbf{1 8 0 0}$ & 1159.651 \\
\hline $\mathbf{2 0 0 0}$ & 329.06 \\
\hline $\mathbf{2 0 7 4 . 5}$ & 0 \\
\hline
\end{tabular}

Plot antara Pwf asumsi dan Q pada Pwf asumsi $\left(Q_{@ P \text { Pf asumsi }}\right)$ menghasilkan IPR untuk sumur L5A-MRS.

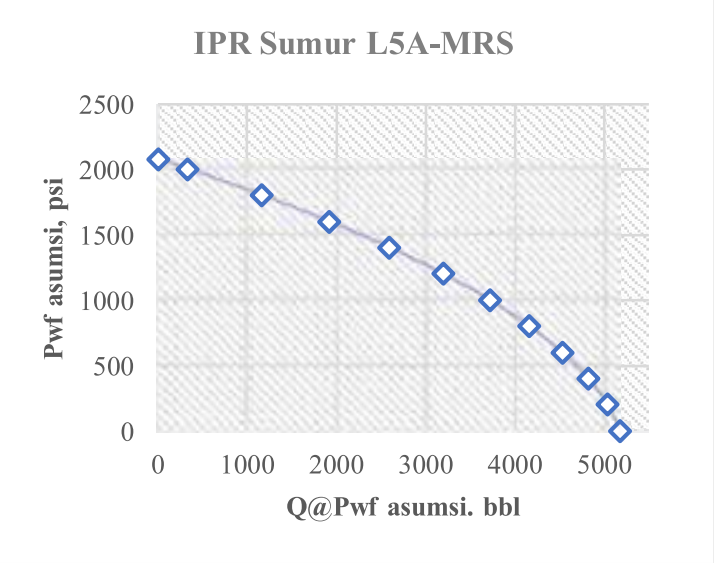

Gambar 2. IPR Sumur L5A-MRS

Untuk melakukan perencaan ulang ESP, terlebih dahulu tentukan rate yang akan diproduksikan (Q desain) dan tekanan pada rate yang akan diproduksikan (Pwf desain).

Agar mendapatkan keuntungan bagi perusahaan, pompa memiliki efisiensi diatas $60 \%$, submergence pompa $\pm 100 \mathrm{ft}$, dan penyesuaian stages yang tersedia, penulis merencanakan Q desain sebesar 4450 bpd pada PSD $4000 \mathrm{ft}$.

Plot Q desain pada grafik IPR (Inflow Performance Relationship), didapatkan tekanan pada $\mathrm{Q}$ desain (Pwf desain). 


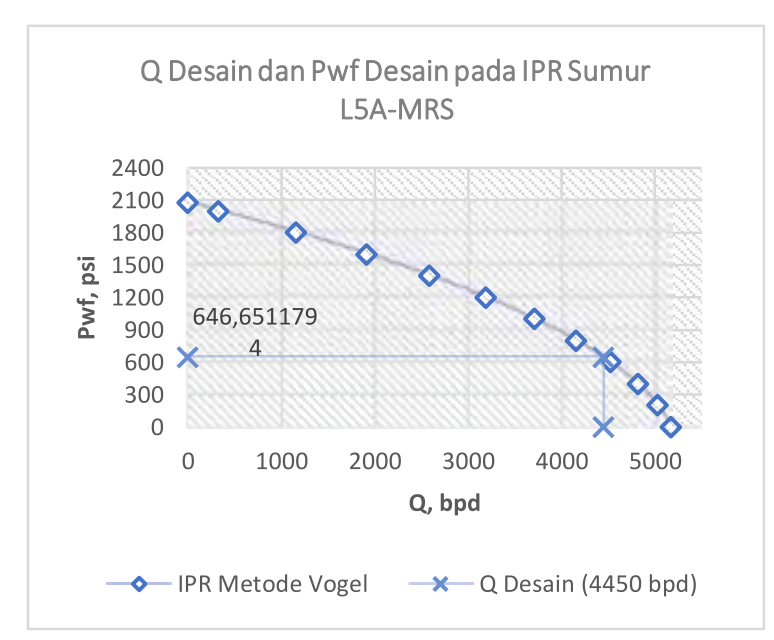

Gambar 3. Q Desain dan Pwf Desain pada IPR Sumur L5A-MRS

Dari hasil plot, didapatkan Pwf pada Q desain (4450 bpd) adalah sebesar 646.65 psi.

Penentuan pompa ESP berdasarkan Q desain dan ketersediaan pompa di workshop. Tentukan pompa ESP yang mempunyai nilai recommended flow range mencakup $\mathrm{Q}$ desain.

Pompa yang mempunyai nilai recommended flow range mencakup $Q$ desain $(4450 \mathrm{bpd})$ adalah pompa ING 4000 pada frekuensi $60 \mathrm{~Hz}$ dengan nilai recommended flow range sebesar 2600 - 5200 bpd.

Setelah menentukan pompa, kemudian menghitung berapa jumlah stages minimal yang diperlukan untuk mengalirkan fluida sampai ke permukaan dengan pompa yang dipilih (ING 4000, 60 Hz). Penentuan jumlah stages menyesuaikan stages yang tersedia. Perhitungan stages yang dibutuhkan sebagai berikut:

Menghitung $\mathrm{SG}_{\mathrm{L}}$ campuran menggunakan persamaan:

SGl mix $=$ (Fraksi air $\times$ SG air $)+$ (Fraksi minyak $\times$ SG minyak)

SGl mix $=(98 \% \times 1.02)+(2 \% \times 0.985)$

SGl mix $=1.0193$
Menghitung PIP (Pump Intake Pressure) menggunakan persamaan:

PIP $=$ Pwf desain-

$\left[\frac{\text { (Datum Depth-Pump Depth) } \times \mathrm{SGl}}{2.31 \mathrm{ft} / \mathrm{psi}}\right]$

$\mathrm{PIP}=646.65-\left[\frac{(5302.658-4000) \times 1.0193}{2.31 \mathrm{ft} / \mathrm{psi}}\right]$

$\mathrm{PIP}=71.8 \mathrm{psi}$

Menghitung Net Dynamic Lift menggunakan persamaan:

Net Dynamic Lift=PSD- $\left(\frac{\text { PIP } \times 2.31 \mathrm{ft} / \mathrm{psi}}{\mathrm{SGl}}\right)$

Net Dynamic Lift $=4000-\left(\frac{71.8 \times 2.31 \mathrm{ft} / \mathrm{psi}}{1.0193}\right)$

Net Dynamic Lift $=3837.253$

Menghitung nilai friction loss pada ID tubing 2.992 inch pada $\mathrm{Q}$ desain $=4450 \mathrm{bpd}$ dengan persamaan:

$\mathrm{F}=2.083 \times\left(\frac{100}{\mathrm{C}}\right)^{1.85} \times \frac{\left(\frac{\mathrm{Q}}{34.3}\right)^{1.85}}{(\mathrm{ID})^{4.8655}}$

$\mathrm{F}=2.083 \times\left(\frac{100}{94}\right)^{1.85} \times \frac{\left(\frac{4450}{34.3}\right)^{1.85}}{(2.992)^{4.8655}}$

$F=91.57 \mathrm{ft} / 1000$

Menghitung total friction loss sepanjang PSD:

Total Friction Loss $=\mathrm{F} \times \mathrm{PSD}$

Total Friction Loss $=\frac{91.57}{1000} \times 4000$

Total Friction Loss $=366.3 \mathrm{ft}$

Konversi wellhead pressure dalam satuan $\mathrm{ft}$. Wellhead pressure pada Pwf desain diasumsi- 
kan sebesar 100 psi.

$\mathrm{WHP}(\mathrm{ft})=\frac{\mathrm{WHP}(\mathrm{psi}) \times 2.31 \mathrm{ft} / \mathrm{psi}}{\mathrm{SGl}}$

WHP $(\mathrm{ft})=\frac{100 \times 2.31 \mathrm{ft} / \mathrm{psi}}{1.0193}$

Menghitung TDH (Total Dynamic Head) dengan persamaan:
$\mathrm{TDH}=$ Net Dynamic Lift + Total Friction Loss + WHP $(\mathrm{ft})$

$\mathrm{TDH}=3837.253+366.3+226.62$

$\mathrm{TDH}=4430.2 \mathrm{ft}$

Menentukan head/stages dari Pump Performance Curve ING 4000, $60 \mathrm{~Hz}$. Plot Q desain 4450 bpd pada Pump Performance Curve ING 4000, $60 \mathrm{~Hz}$.

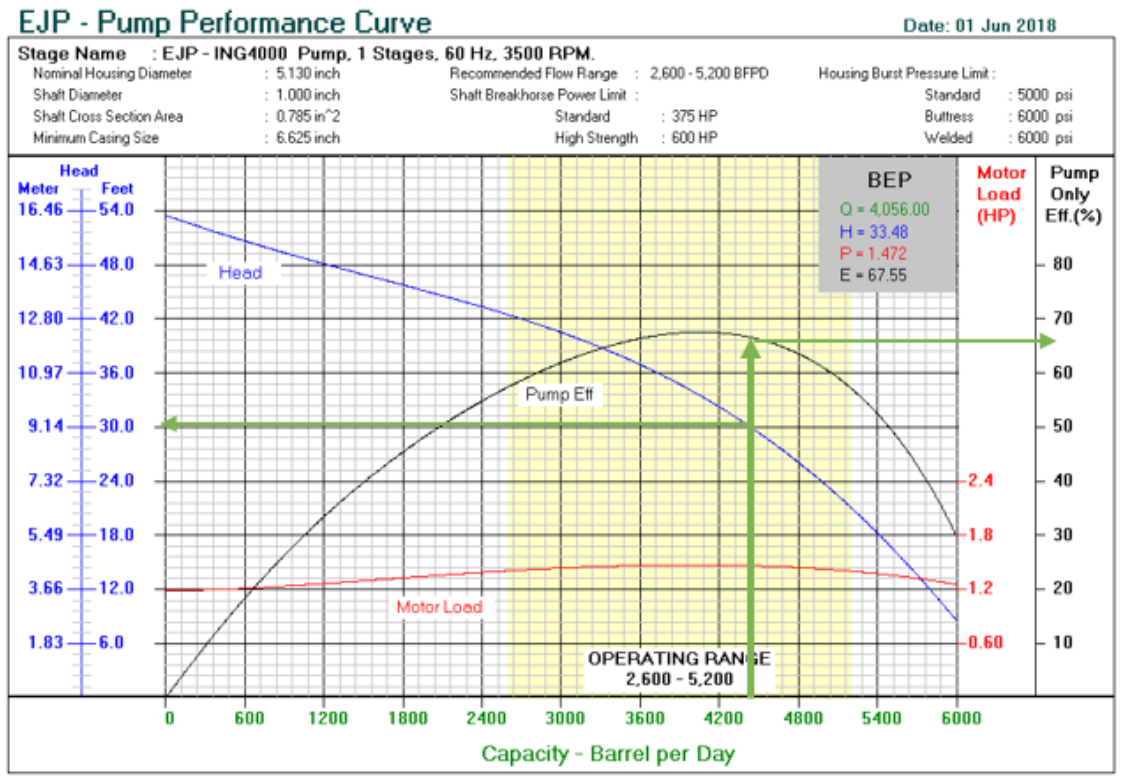

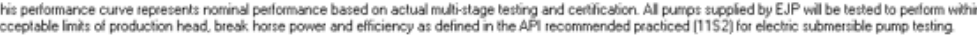

Gambar 4. Plot Q Desain pada Pump Performance Curve ING 4000

Dari plot didapatkan nilai head/stages sebe- Stages minimal yang dibutuhkan pompa unsar $31 \mathrm{ft} /$ stages dan efisiensi pompa 66\%.

Jumlah stages minimal dihitung dengan pertuk mengalirkan fluida sampai ke permukaan adalah sebanyak 143 stages. samaan:

Stages $=\frac{\mathrm{TDH}}{\text { head/stages }}$

Stages $=\frac{4430.2}{31}$

Stages $=142.9(143$ stages $)$

\section{Kesimpulan}

Berdasarkan hasil evaluasi pompa terpasang dan perencanaan ulang, maka dapat diambil kesimpulan sebagai berikut:

1. Setelah dilakukan evaluasi, pompa yang terpasang (ING 3200) mengalami permasalahan kondisi upthrust, kelebihan 
beban muatan (overloaded condition), dan efisiensi pompa yang sangat rendah (55\%).

2. Pompa desain (ING 4000) direncakan pada Q desain 4450 bpd, Pwf desain
646.65 psi, PSD $4000 \mathrm{ft}$.

3. Efisiensi pompa ING 4000 mencapai $66 \%$ dengan $\mathrm{Q}$ produksi yang lebi besar dari pompa ING 3200 .

\section{Daftar Pustaka}

Brown, KE, 1977, "The Technology of Artificial Lift", Volume 1, Tulsa:Petroleum Publishing Company.

Centrilift, 1997, “Electric Submersible Pump Handbook”, Oklahoma: Centrilift. 